\title{
Incidental findings in patients evaluated with cone beam computed tomography for orthodontic treatment
}

\author{
Achados incidentais em tomografia computadorizada de feixe cônico em pacientes avaliados para trata- \\ mento ortodôntico
}

Everton FLAIBAN ${ }^{1}$

Maria Beatriz Carrazzone Cal ALONSO 2

Cláudio Fróes de FREITAS 3

Fernando César TORRES²

Michel Lipiec-XIMENES ${ }^{3}$

André Luiz Ferreira COSTA ${ }^{2}$

\section{ABSTRACT}

\section{Objective}

The aim of this retrospective study was to determine and quantify incidental findings in CBCT scans taken exclusively for orthodontic purposes.

\section{Methods}

A total of 202 scans were evaluated by two examiners and classified into five different groups.

\section{Results}

A total of 227 incidental findings were found in a sample of patients aged 5-58 years old. The highest number of findings was of dental origin $(n=157)$, followed by airway $(N=46)$, skull $(N=16)$ and ATM $(n=8)$. Scans with no incidental finding accounted for $20 \%$ of the examinations. Subjects having lower mean age were found in the group of airway findings. The prevalence of incidental findings in the current study was consistent with the literature, thus corroborating their high frequency. Orthodontists who make use of CBCT are responsible for assessment of all data.

\section{Conclusion}

The precise evaluation of incidental findings may help in the early diagnosis, treatment and patient monitoring. Further studies should be conducted to assess the influence of these findings on the orthodontic treatment.

Indexing terms: Diagnostic imaging. Incidental findings. Orthodontics.

\section{RESUMO}

Objetivo

Investigar e quantificar achados incidentais em exames de tomografia computadorizada de feixe cônico realizadas unicamente para fins ortodôntico.

\section{Métodos}

Foram incluídos os exames de tomografia de feixe cônico com finalidade de diagnóstico ortodôntico no período de novembro de 2011 a abril de $2014(n=202)$ avaliados por dois examinadores e os dados coletados classificados em cinco grupos diferentes. Foi realizada análise exploratória dos dados através do cálculo de média, desvio padrão, frequência e porcentagem. A associação entre o local do achado e o gênero foi verificada através do teste exato de Fisher.

\section{Resultados}

Foi encontrado um total de 227 achados; o grupo com maior número de achados foi o de origem dental ( $n=157)$, seguido do grupo de vias aéreas $(n=46)$, de crânio $(n=16)$ e de ATM $(n=8)$. Exames sem nenhum achado representaram $20 \%$ do total. Os sujeitos com menores médias de idade foram encontrados no grupo de vias aéreas. A prevalência de alterações tomográficas incidentais em pacientes ortodônticos é alta.

\section{Conclusão}

Um cuidadoso diagnóstico das imagens de tomografia de feixe cônico além da região de interesse ortodôntica é indispensável para prevenir patologias ocultas. Estudos adicionais podem ser realizados para avaliar qual a influência desses achados no tratamento ortodôntico.

Termos de indexação: Tomografia. Diagnóstico por imagem. Ortodontia.

\footnotetext{
${ }^{1}$ Universidade Cruzeiro do Sul, Programa de Pós-graduação em Ortodontia. Av. Nove de Julho, 4701, Jardim Paulista, 01407200, São Paulo, SP, Brasil. Correspondência para / Correspondence to: E FLAIBAN. E-mail: <evertonflaiban@hotmail.com>.

2 Universidade Cidade de São Paulo, Programa de Pós-graduação em Odontologia. São Paulo, SP, Brasil.

3 Universidade de São Paulo, Faculdade de Odontologia, Departamento de Estomatologia. São Paulo, SP, Brasil.
} 


\section{INTRODUCTION}

The use of cone beam computed tomography (CBCT) as initial exam for diagnosing orthodontic patients is a trend in orthodontics and has become a tool necessary in the diagnosis and treatment planning. With its image quality and accuracy attracting more and more adepts, CBCT has been used for auxiliary diagnosis of craniofacial disorders and malocclusions, exact localisation of impacted canines, orthognathic surgery, temporomandibular disorders and placement of anchorage mini-screws ${ }^{1}$.

Studies have recently reported that significant changes in the face, skull and maxilla in patients who were submitted to $C B C T$ for routine orthodontic diagnosis². These changes, termed as incidental findings, are common but its meaning and importance in the unleashing of some disorder, if any, are still unknown. The frequencies of these occasional findings vary very much from study to study depending on age groups, study population and category of findings.

According to the American Academy of Oral and Maxillofacial Radiology, the choice of the modality to be used for imaging examination of orthodontic patients is based on a risk/benefit evaluation (i.e. patient's exposure to radiation versus benefits of imaging procedure), showing a concern about the increasing number of $C B C T$ examinations ${ }^{3}$.

Most findings which are occasionally found result in referrals to other dental specialists or even physicians s, $^{1,5}$. Jung-Yul et al. ${ }^{1}$ reported that the overall rate of maxillofacial incidental findings on CBCT scans of 500 patients was of 24.6 percent, with the highest rate being found in the airways.

Price et al. ${ }^{4}$ reported that 16.1 percent of the 871 incidental findings on 300 CBCT scans required a definitive intervention. Some issues may be raised with the knowledge of these recently reported data, such as influence of them on the orthodontic planning and treatment, severity of the disease and outcome to the patient's general health. Another questioning is about the preoccupation of orthodontists with these findings and their role in view of the report of this diagnosis.

Therefore, the objective of this study was to detect and quantify incidental findings on CBCT scans of orthodontic patients.

\section{METHODS}

The study project was approved the Research Ethics Committee of the City of São Paulo University under protocol number 877.303. This study was conducted in accordance with the ethical standards established by the Declaration of Helsinki and World Medical Association in 1964 and amended in 1996. This is an observational, crosssectional study assessing a sample of 202 CBCT scans of patients consecutively taken between November 2012 and April 2014 at the Institute of Orthodontic Documentation and Diagnostic Radiology for orthodontic purposes only.

CBCT images were obtained with the i-CAT Imaging System (Imaging Sciences International Inc. Hatfield, USA). The files in DICOM format were recorded in a computer and visualised by using the NemoScanNxPro software (Nemotec SL, Madrid, Spain). The images were jointly assessed by two examiners (one orthodontist and one radiologist), and in the case of diagnostic divergence, the images were discussed until a consensus was reached.

The data collected were divided into five different groups according to criteria of occurrence and localisation $(5,6)$.

a) Cranial findings (skull)

b) Dental findings (teeth, maxilla and mandible)

c) Airway findings

d) Temporomandibular joint findings (TMJ)

e) No incidental findings

Some findings can be seen in Figure 1.
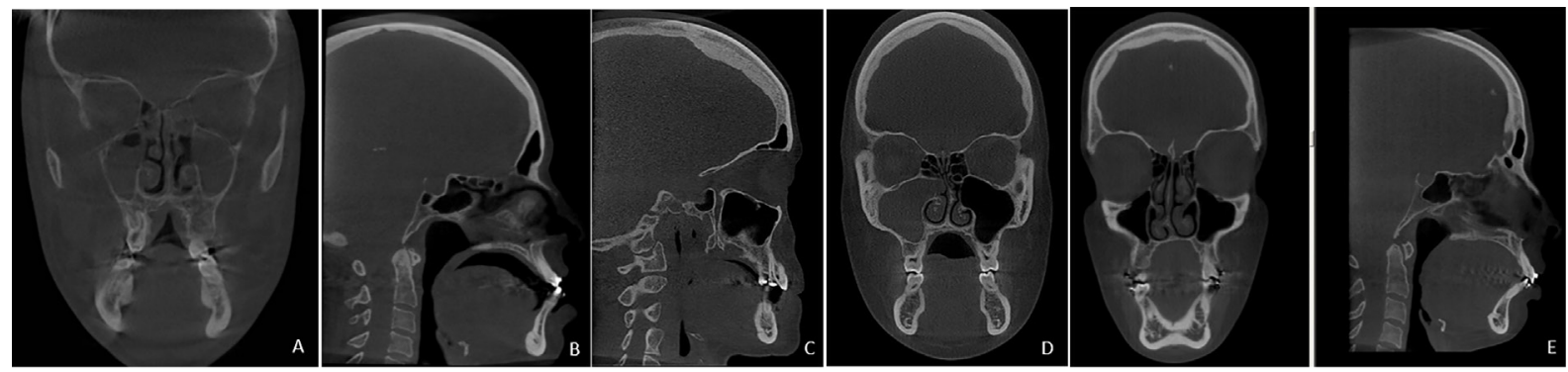

Figure 1. A. Sinusitis, B. Radiopaque image in the centre of the skull cap, C. Internal frontal hyperostosis, D. Sinusitis on the left side, E. Radiopaque image in the centre of the skullcap. 
In the group of dental findings, the most common occurrences such as absence of third molars, absence of teeth, endodontic treatment and unerupted third molars were generically grouped without any specific detail regarding teeth and regions involved, thus avoiding an excessive number of different findings. These data were tabulated and statistically analysed.

\section{RESULTS}

An exploratory data analysis was performed by calculating mean, standard deviation, minimum, median and maximum values, including frequency and percentage and construction of graphs. The mean age between the groups of findings was compared by using the KruskalWallis non-parametric test followed by Dunn's multiple comparison test. The relationship between location of the finding and gender was assessed by using the Fisher's exact test. All analyses were performed with a statistic software ( $R$ Core Team, $\vee$ 3.0.2. Language and Environment for Statistical Computing, Vienna, Austria) at 95\% confidence interval.

Incidental findings were observed in two or more locations for some patients. Figure 2 shows the distribution in percentage of patients regarding each location or group of findings. The locations skull $(n=5)$, teeth/TMJ $(n=3)$, TMJ $(n=4)$, airways/teeth/skull $(n=2)$ and airways/TMJ ( $n$ $=1$ ) were grouped into another category for assessment of the relationship between location of finding and both gender and age, as shown in Figure 3.

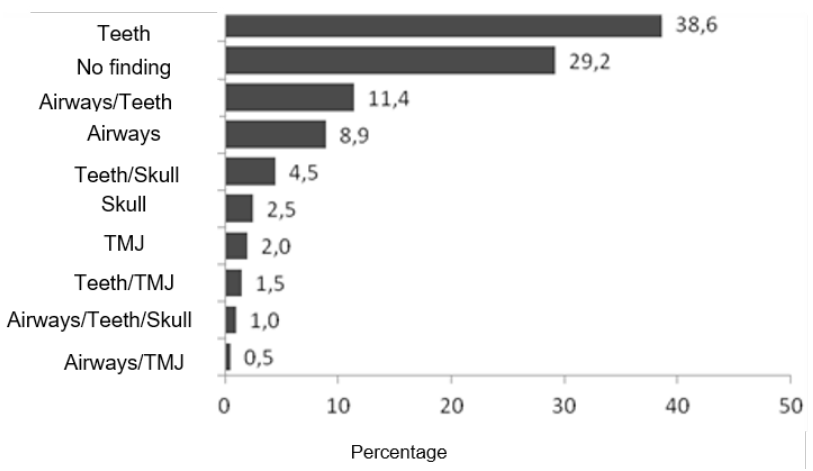

Figure 2. Percentage of patients and each location or group of locations. Note: Teeth; No finding; Airways/Teeth; Airways; Teeth/Skull; Skull; TMJ; Teeth/TMJ; Airways/Teeth/Skull; Airways/TMJ.

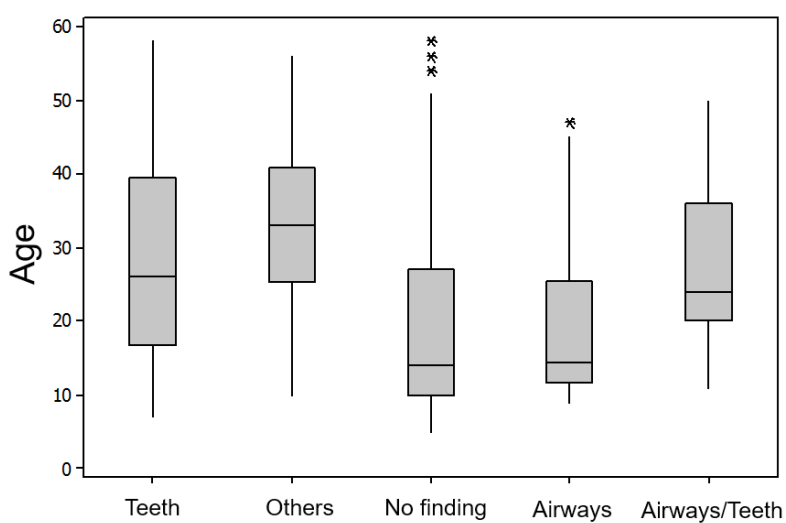

Figure 3. Box-plot of age for location of incidental findings.

The age of the patients ranged from 5 to 58 years old, with mean age of 25.62 and standard deviation of 13.14. Statistically significant differences were found between finding locations and age (Kruskal-Wallis; $P$-value $<0.00001)$. The Dunn's test showed that the groups of no finding had a lower mean age compared to the other groups, except the airway group. This location had the lowest mean age among all groups. No statistically significant differences were found between the others.

With regard to the relationship between location of the finding and gender (Fisher's exact test, $P$-value $=$ 0.292), no statistically significant difference was found. A total of 227 incidental findings were found on 202 CBCT scans, with the dental group having the highest number (n $=157)$, followed by airway group $(n=46)$, skull group $(n=$ 16) and TMJ group $(n=8)$.

The main incidental finding in the dental group was the absence of third molars $(n=63)$, followed by absence of other teeth $(n=31)$, unerupted third molars ( $n$ $=18)$, endodontic treatment $(n=10)$, periapical lesion ( $n$ $=8)$, external root resorption $(n=8)$, bone condensation $(n=6)$, other unerupted teeth $(n=4)$, altered eruption pathway $(n=3)$, infra-occluded tooth $(n=1)$, periodontal problem $(n=1)$, and supernumerary teeth $(n=1)$.

In the airway group, sinusitis was the most prevalent incidental finding $(n=41)$, whereas other findings were detected in a very small number such as polyps $(n=2)$, maxillary sinus communication $(n=1)$, sinus mucosal thickening $(n=1)$ and airway narrowing $(n=1)$.

The findings in the TMJ group were only three, namely, condylar erosion ( $n=5)$ condylar atrophy $(n=2)$ and bifid condyle $(n=1)$. In the skull group, the incidental findings were cranial calcification $(n=12)$, internal frontal 
hyperostosis $(n=3)$ and calcification in the anterior lobe region $(n=1)$.

\section{DISCUSSION}

Incidental findings on CBCT scans are an issue which has been of concern among the majority of the authors who study this theme due to a lack of knowledge on its significance and possible clinical interventions.

In the present study, the prevalence of incidental findings on CBCT scans was significantly high ( $n=227$ for 202 scans), which is also corroborated by other works. Drage et al. ${ }^{6}$ reported a higher number of incidental findings ( $n=370$ for 329 scans), with at least one incidental finding in 66 percent of the patients. Similar results were found by Rheem ${ }^{7}$, who detected incidental findings on 59 scans, or 40.1 percent, in a sample of 147 patients.

In the present study, no statistical differences were found between location of incidental findings and gender. A similar result was found by Pazera et al. ${ }^{8}$, who reported that the frequency of incidental findings seemed not to be related to gender. This intriguing result was also observed by Rheem et al. ${ }^{7}$, who demonstrated statistically that women are 2.58 times more likely to present some type of incidental finding in the region of TMJ compared to men. Edwards et al. also support these results as they found similar figures, that is, women were 2.55 times more likely to present such incidental findings than men. However, our results do not support the above-mentioned studies, since the number of incidental findings in the TMJ group was small and not related to gender or age.

The group with no incidental finding had a mean age lower than that of the other groups, that is, results similar to those found by Pliska et al. ${ }^{5}$, who revealed significant correlations between age and number of incidental findings as the former increases so does the latter. However, they found no correlation between age and incidental findings in the airways or other locations. Our statistical analysis showed different figures regarding the airways, since this group had a lower mean age compared to other groups. Similar results were found by Jung-Yul et al. ${ }^{1}$, who reported that sinusitis was the main type of incidental finding in the airways and that 58.3 percent of these patients were aged between 12 and 16 years old. Çağlayan \& Tozglu ${ }^{9}$ states that the high frequency of incidental findings in the airways demonstrates that CBCT can be an efficient tool for detecting changes in the respiratory pathways. In fact, sinusitis $(n=46)$ accounted for the highest number of incidental findings in the airway group, this expressive result was entirely based on radiographic appearance, since no clinical information was evaluated. Drage et al. ${ }^{6}$ states that the results regarding maxillary sinuses are little related to clinical signs and symptoms, suggesting that it is likely that many patients are asymptomatic and thus demand no treatment (even in the presence of positive radiological findings).

Calcifications in the central region of the skull were found in 12 CBCT scans, but this result is not representative in the prevalence of this type of calcification in the population. The prevalence of calcification in the pineal gland is of 20 percent, although it can reach 46 percent in patients older than 40 years ${ }^{10}$.

Our results show a high number of absence of third molars, differing from previous studies 1 4-5,11. Edwards et al. ${ }^{11}$ explains that the lack of third molars should be considered an incidental finding, since these teeth are often missing or may have been previously extracted.

Tomographic scans performed for orthodontic purposes should be judiciously evaluated (i.e. considering axial, coronal and sagittal planes) to disregard any pathological alterations and to refer the patient to a specialist, if necessary ${ }^{3,12-13}$.

\section{CONCLUSION}

In view of the results described here, one can conclude that the prevalence of incidental findings on CBCT scans taken for orthodontic purposes is high and therefore should serve as a warning for evaluating and interpreting the whole scanned area. We emphasise that further studies should be performed to investigate the influence of these incidental findings on the orthodontic treatment

\section{Collaborators}

E FLAIBAN, design and conceptualization of the study, analysis and interpretation of the data, drafting and revising the manuscript. MBCC ALONSO, drafting and revising the manuscript. CF FREITAS, analysis and interpretation of the data. FC TORRES, analysis and interpretation of the data. M LIPIEC-XIMENES, acquisition, analysis and interpretation of the data. ALF COSTA, design and conceptualization of the study, analysis and interpretation of the data, drafting and revising the manuscript. 


\section{REFERENCES}

1. Jung-Yul C, Mah J, Peter Sinclair P. Incidental findings in the maxillofacial area with 3-dimensional cone-beam imaging. Am J Orthod Dentofacial Orthop. 2007;132;7-14. doi: 10.1016/j. ajodo.2005.08.041

2. Edwards R, Altalibi M, Flores-Mir C. The frequency and nature of incidental findings in cone-beam computed tomographic scans of the head and neck region: a systematic review. J Am Dent Assoc. 2013 Feb;144(2):161-70. doi: 10.1016/j. ajodo.2005.08.041

3. American Academy of Oral and Maxillofacial Radiology. Clinical recommendations regarding use of cone beam computed tomography in orthodontics: position statement by the American Academy of Oral and Maxillofacial Radiology. Oral Surg Oral Med Oral Pathol Oral Radiol. 2013 Aug;116(2):23857. doi: 10.1016/j.0000.2013.06.002

4. Price JB, Thaw KL, Tyndall DA, Ludlow JB, Padilla RJ. Incidental findings from cone beam computed tomography of the maxillofacial region: a descriptive retrospective study. Clin Oral Implants Res. 2012 Nov;23(11):1261-8. doi: 10.1111/j.16000501.2011.02299.x

5. Pliska B, De Rocher $M$, Larson B. Incidence of significant findings on CBCT scans of an orthodontic patient population. Northwest Dent. 2011 Mar-Apr;90(2):12-6.

6. Drage N, Rogers S, Greenall C, Playle R. Incidental findings on cone beam computed tomography in orthodontic patients. J Orthod. 2013 Mar;40(1):29-37. doi: $10.1179 / 1465313312$ Y.0000000027

7. Rheem S, Nielsen IL, Oberoi S. Incidental findings in the maxillofacial region identified on cone-beam computed tomography scans. J Orthod Res. 2013;1:33-9.
8. Pazera $\mathrm{P}$, Bornstein MM, Pazera A, Sendi $\mathrm{P}$, Katsaros $\mathrm{C}$. Incidental maxillary sinus findings in orthodontic patients: a radiographic analysis using cone-beam computed tomography (CBCT). Orthod Craniofac Res. 2011 Feb;14(1):17-24. doi: 10.1111/j.1601-6343.2010.01502.x

9. Çağlayan F, Tozoğlu U. Incidental findings in the maxillofacial region detected by cone beam CT. Diagn Interv Radiol. 2012 Mar-Apr;18(2):159-63. doi: 10.4261/1305-3825.DIR.4341-11.2

10. Kitkhuandee A, Sawanyawisuth K, Johns J, Kanpittaya J, Tuntapakul S, Johns NP. Pineal calcification is a novel risk factor for symptomatic intracerebral hemorrhage. Clin Neurol Neurosurg. 2014 Jun;121:51-4. doi: 10.1016/j.clineuro.2014.03.019.

11. Edwards R, Alsufyani N, Heo G, Flores-Mir C. The frequency and nature of incidental findings in large-field cone beam computed tomography scans of an orthodontic sample. Prog Orthod. 2014 Jun 11;15(1):37. doi: 10.1186/s40510-014-0037-x

12. Barghan S, Tetradis S, Nervina J. Skeletal and soft-tissue incidental findings on cone-beam computed tomography images. Am J Orthod Dentofacial Orthop. 2013 Jun;143(6):88892. doi: 10.1016/j.ajodo.2012.03.037

13. Gracco A, Parenti SI, loele C, Bonetti GA, Stellinid E. Prevalence of incidental maxillary sinus findings in Italian orthodontic patients: a retrospective cone-beam computed tomography study. Korean J Orthod. 2012; 42(6):329-334. doi: 10.4041/ kjod.2012.42.6.329 